\title{
UMA ANÁLISE DOS TEXTOS DE FREDERICK FORBES NAS DÉCADAS DE 1840-1850. O ESQUADRÃO AFRICANOE O FINAL DO TRÁFICO ESCRAVO NA ÁFRICA OCIDENTAL.
}

ALEXSANDER GEBARA

Universidade Federal Fluminense

\section{RESUMO}

O artigo trata dos relatos das viagens do inglês Frederick $E$. Forbes a Daomé no século XIX, documentos que têm sido amplamente utilizados na historiografia sobre a África ocidental. O objetivo é examinar, nos relatos de Forbes, seu ponto de vista sobre o tráfico atlântico de escravos, uma preocupação da Inglaterra na $1^{a}$ metade do século XIX com relação à costa africana.
PALAVRAS-CHAVE: relatos de viagem; Frederick Forbes; tráfico atlântico de escravos.

\section{ABSTRACT}

The article focus on the Frederick Forbes travels to Dahomey in the 19th century. These documents are well known in the historiography of Western Africa, but the author aims to examine Forber's perceptions of the Atlantic slave trade, an England concern regarding the African coast in the first half of the $19^{\text {th }}$ century. 
O nome de Frederick E. Forbes é relativamente conhecido dos historiadores que tiveram sua atenção em algum momento voltada para a história do Daomé no século XIX. Seu relato Dahomey and the Dahomans vem sendo usado amplamente como fonte para a história do reino da África Ocidental. ${ }^{1}$ Resultado de duas viagens diferentes ao reino africano nos anos de 1849 e 1850, participando da comitiva britânica que negociava com o então rei Gezo a cessação do tráfico atlântico de escravos, o livro em questão conta com uma longa e detalhada descrição dos 'costumes anuais' daomeanos, ou seja, sobre o período no qual se reuniam na capital grande parte da elite do reino, 0 exército, as amazonas e diversos outros extratos da sociedade daomeana para o festival em homenagem aos reis anteriores.

Para mencionar apenas alguns nomes dessa historiografia, podemos destacar, por exemplo, John Yoder, que utilizou amplamente o relato de Forbes em seu artigo sobre o contexto político de Daomé em meados do século. ${ }^{2}$ Também Robin Law fez uso extensivo do texto de Forbes em uma série de artigos sobre a região, quer seja para discutir a interpretação apresentada por Yoder ou mesmo para contextualizar o final do tráfico atlântico, ou ainda para propor outras interpretações sobre as tradições culturais daomeanas. ${ }^{3}$

Edna Bay, autora do importante estudo Wifes of the Leopard, ${ }^{4}$ também se refere constantemente ao autor em seu artigo sobre as mudanças na forma dos 'costumes anuais' do reino da África Ocidental. Tal artigo, significativamente intitulado On the Trail of the Bush King: a Dohomean Lesson in the Use of Evidence ${ }^{5}$ propõe a necessidade de uma leitura mais crítica dos relatos de viagem para ampliar suas possibilidades de utilização como fontes históricas.

Segundo a autora, "os historiadores do século XX, até agora não os avaliaram adequadamente [os relatos de viagem sobre o Daomé], nem os utilizaram para produzir uma história compreensiva do reino, ou uma descrição de suas instituições." 6 Muitos teriam apenas utilizado a vasta produção de relatos sobre a região para extrair 'dados', tornando-se assim mais compiladores do que intérpretes da história daomeana. Ainda segundo ela: "Os

\footnotetext{
${ }^{1}$ FORBES,John. Dahomey and the Dahomans: being the journals of two missions to the king of Dahomey, and residence at his capital in the years 1849-1850. London: Longman, Brown, Green, and Longmans, 1851.

2 YODER, John. Fly and Elephant parties: Political Polarization in Dahomey, 1840-1870. The Journal of African History, vol. 15, n 3, 1974, p. 417-432.

3 LAW, Robin. 'My head belongs to the King': on the political and Ritual significance of decapitation in pre-colonial Dahomey. The Journal of African History, vol. 30, n. 3, 1989, p. 399-415; Politics of commercial transition: factional conflicts in Dahomey in the context of the ending of Atlantic Slave Trade. Journal of African History, vol. 38, 1997, pp. 213-233; Human Sacrifice in pre-colonial West Africa. African Affairs, vol. 84, n 334, 1985, p. 53-87.

${ }^{4}$ BAY, Edna. Wifes of the Leopard: gender, politics and culture in the Dahomey Kingdom. Charlottesville: University of Virginia Press, 1998.

${ }^{5}$ BAY, Edna. On the Trail of the Bush King: a Dohomean Lesson in the Use of Evidence. History in Africa, vol. 6, 1979, pp. 1-15. (Na trilha do rei da Floresta: uma lição daomeana sobre o uso das evidências) Todas as traduções neste texto de obras e fontes originalmente em inglês são minhas.

${ }^{6}$ BAY, Edna. On the trail... p. 3
} 
viajantes pré-coloniais raramente foram lidos criticamente, quer em comparação com as fontes orais já coletadas, ou simplesmente frente às próprias inconsistências internas ao seu próprio texto." ${ }^{7}$

Parece claro que a historiografia das últimas décadas tornou essas críticas relativamente superadas. Para isso, basta citar a própria produção de Robin Law, que utiliza brilhantemente não apenas Forbes, mas vários outros autores com grande maestria e consistência.

Entretanto, ainda há outros aspectos pouco trabalhados na crítica sobre os relatos de viagem que ainda podem ajudar na compreensão desses textos. A intenção deste artigo é pensar este texto de Forbes não em comparação com outros relatos ou com fontes orais, mas sim frente a trabalhos do próprio autor em outros momentos de sua produção, em especial no que diz respeito à sua opinião sobre o tráfico atlântico de escravos, como se sabe, uma das principais preocupações da Inglaterra na primeira metade do século XIX com relação à costa ocidental africana.

Parece também bastante certo que é impossível separar os projetos políticos dos autores do conteúdo de suas descrições na África ou em outro lugar qualquer. ${ }^{8}$ Temas, ênfases e silêncios presentes nos relatos de viagem estão em relação direta com argumentos e projetos políticos de seus autores. A descrição do africano 'bárbaro', 'cruel', 'irracional' pode servir, por exemplo, para legitimar a intervenção forçada e o controle do comércio na costa africana. Mas o inverso também pode ser verdade; o africano 'dócil' e 'civilizável' pode servir como legitimação para intervenção em outros lugares que estivessem ameaçando o desenvolvimento da 'civilização' na própria África.

Dessa forma, a imagem do 'africano' e sua relação com o tráfico atlântico são importantes elementos para que seja possível compreender com mais complexidade a motivação das ênfases e dos silêncios nos textos analisados. É momento, então, de observar um pouco mais de perto a produção textual de Forbes ao longo do tempo, refletindo sobre as suas congruências e, mais importante, sobre suas incongruências.

\footnotetext{
${ }^{7}$ Idem.

${ }^{8}$ Particularmente, abordei este tema com algum vagar em GEBARA, Alexsander. A África de Richard Francis Burton: Antropologia, Política e Livre Comércio (1861-1865). São Paulo: Alameda, 2010.

${ }^{9}$ Em meu livro já citado, discuto esta questão. Por exemplo, a cidade Egba de Abeokuta, vista por alguns na Inglaterra como "o nascer do sol nos trópicos' - título de um livro de Sara Tucker sobre a região - estaria sob constante ameaça do poder cruel, bárbaro e escravista do Daomé, por volta da metade do século XIX. Estes argumentos eram utilizados mesmo que em Abeokuta ainda houvesse um comércio de escravos residual, e certamente a instituição da escravidão profundamente arraigada no corpo social. GEBARA, Alexsander. A África de Richard Burton... em especial cap. 4.
} 


\section{Frederick Forbes - viajante, escritor e militar}

As análises propostas aqui estão baseadas numa série de textos de Forbes que fornecem uma perspectiva um pouco mais aprofundada sobre sua presença nas regiões de expansão do império britânico em meados do século XIX. Conhecido principalmente pelo seu relato sobre o Daomé, o autor também publicou algumas outras obras, dentre elas, duas que também abordaremos neste artigo, quais sejam, Five Years in China, e Six Months' Service in the African Blockade. ${ }^{10}$

Não se trata de fazer uma análise exaustiva das obras, mas de perceber em linhas gerais como o autor descrevia as relações britânicas com as áreas nas quais visitou e mapear esses posicionamentos, em especial frente ao contexto de combate ao tráfico escravo na metade do século XIX.

$\mathrm{Na}$ ausência de uma biografia do autor, as informações sobre sua carreira se resumem, neste momento, ao que ele mesmo informa incidentalmente em seus relatos. Pode-se traçar então, a partir desses dados, um breve panorama de sua atuação na marinha britânica. $\mathrm{O}$ autor teria entrado para a Royal Navy em 1833, alocado para servir nas Índias Ocidentais, onde permaneceu até 1842, quando foi deslocado para a China. Esteve no oriente por cinco anos, parte dos quais empregados em uma viagem para o interior, mas também participando das incursões marítimas que resultaram na ocupação de Bornéu. Já tendo assumido a patente de tenente foi deslocado para o esquadrão britânico de combate ao tráfico de escravos (Esquadrão Africano) na costa ocidental da África, provavelmente no final de 1847. Nos anos seguintes, continuou participando da captura de navios escravistas e esteve também em duas das famosas missões enviadas para negociar o final do tráfico de escravos com o rei Gezo do Daomé. ${ }^{11}$

Como não há um relato específico sobre sua presença nas Índias Ocidentais, a análise começará com uma breve apreciação do seu relato sobre o extremo oriente, escrito, segundo ele, para "aliviar o tédio de uma longa viagem marítima", provavelmente para a Inglaterra, antes de se dirigir à costa ocidental africana. ${ }^{12}$ Segundo Forbes, ele chegou na China a tempo de presenciar "as últimas hostilidades". Entretanto, essa constatação vem seguida de uma afirmação bastante significativa, qual seja, a de que no momento em que seu relato estava sendo publicado ele supunha que:

\footnotetext{
${ }^{10}$ FORBES, F. E. Five Years in China from 1842 to 1847. With an account of the occupation of the islands of Labuan and Borneo by Her Majesty's Forces. London: Richard Bentley, 1848, e Six Month's Service in the African Blockade from April to October 1848. London: Richard Bentley, 1849.

${ }^{11}$ Estas informações constam em seus relatos de viagem. No prefácio de Six Month 's Service in the African Blockade, from april to October, 1848, in command of Bonneta. London: Richard Bentley, 1849, Forbes menciona que suas opiniões não eram baseadas apenas na experiência na costa africana, mas em nove anos de permanência nas Índias Ocidentais, de onde se infere que foi para lá em 1833, já que em 1842 já estava na China.

${ }^{12}$ FORBES, F. E. Five Years in China.. p. 1.
} 
(...) estas hostilidades devem ter encontrado um cronista mais hábil há muito tempo, então, confino-me à descrição do que pude apreender das maneiras, costumes e peculiaridades do país e de seus habitantes. ${ }^{13}$

Dessa forma, o autor evita tocar no tema que era de fato o motivo pelo qual esteve servindo na China por cinco anos, ou seja, a chamada Guerra do Opio e suas consequências imediatas. A ausência desse tema em seu texto pode ser compreendida, talvez, como uma estratégia de Forbes para esquivarse de omitir uma opinião sobre os conflitos e suas motivações.

Ora, trata-se de um episódio modelo para exemplificar a atuação "imperial" inglesa na metade do século XIX, com a imposição de um comércio pernicioso a um país soberano que tentava impedi-lo, com intuito de equilibrar a balança comercial inglesa com a China, grande exportadora de chá. Não tocar nessas questões implica numa certa naturalização - mesmo que pela estratégia do silêncio - da atuação britânica. O comércio do ópio não parece suscitar questões humanitárias no autor, apesar de ser reconhecidamente degradante, dada a proibição total de sua importação pela própria Inglaterra.

Se, por um lado, não há praticamente nenhuma menção à Guerra do Ópio no relato, por outro, Forbes participou diretamente da batalha contra Bornéu, e dedica um capítulo específico a esses acontecimentos. ${ }^{14}$ Mas, dada a postura do autor, era esperado que pouco informasse o leitor também sobre as motivações e o desenrolar desses eventos.

O sultão foi acusado de matar seu tio [...] e várias outras autoridades, que eram reconhecidamente amigáveis para com os britânicos. Em parte para vingar estas mortes, e em parte para punir certos atos de pirataria, e uma tentativa de assassinar o Capitão Egerton, os fortes do rio Brune foram destruídos [...] O sultão e seus súditos abandonaram a cidade. Foi feita então a promessa de acabar com as hostilidades se o sultão abandonasse suas piratarias e cedesse a ilha de Labuan na embocadura do rio Brune para os Britânicos para sempre. ${ }^{15}$

Esse é um dos primeiros parágrafos do capítulo e nenhuma outra informação sobre as motivações britânicas ou possíveis resistências nativas surgem no restante do texto. Assim, é com informações parciais (certos atos de pirataria, supostos assassinatos) para legitimar a atitude da marinha britânica e nenhuma resistência digna de nota, que a imposição da norma britânica aparece como absolutamente natural, sem contestação, e assim sem a necessidade de uma explicação mais elaborada.

O silêncio e a naturalização, portanto, foram as estratégias adotadas pelo autor para tratar da Guerra do Ópio e de escaramuças resultantes da

\footnotetext{
${ }^{13}$ FORBES, F. E. Five Years in China.. p. 2.

${ }^{14}$ Capítulo XVII do relato em questão.

${ }^{15}$ FORBES, F.E. Five Years in China... p. 285.
} 
presença incisiva da marinha britânica nos mares do extremo oriente. Essa estratégia torna possível apresentar uma visão relativamente positiva da China para os leitores ingleses. Livre das necessidades de justificativa para a atuação inglesa, o povo chinês não precisa ser retratado como bárbaro ou inferior para legitimar a intervenção militar britânica.

Assim, os "chineses" descritos por Forbes podem aparecer sob lentes amenas, sendo inclusive possível compará-los com os ingleses. Segundo o autor, a imagem negativa dos chineses normalmente veiculada na Inglaterra diz respeito apenas ao porto de Cantão, e esses não representariam a maior parte da população. Segundo ele,

depois de um primeiro sopro de hostilidades, e uma pequena irritação em consequência da derrota, a qual um inglês pode muito bem aturar e compreender, eu me encontrei em meio a uma população cordial, gentil e hospitaleira, um tanto à nossa frente em algumas coisas quanto atrasadas em outras. ${ }^{16}$

Novamente, pode-se notar a naturalização da superioridade do inglês vitorioso na guerra e capaz de compreender as hostilidades iniciais chinesas oriundas da derrota. Mas, por outro lado, a população aparece como "cordial" e "gentil", e ele sugere mesmo - como se vê na citação acima - "à frente dos ingleses em algumas coisas", embora não explique exatamente quais. Em diversos momentos do texto, os chineses aparecem como "industriosos", a sua agricultura é "bem desenvolvida", suas cidades são limpas, etc... É desnecessário multiplicar os exemplos da perspectiva de Forbes sobre a população, basta reter que a imagem geral apresentada pelo autor não precisa inferiorizar o nativo o tempo todo. A relação posicional entre ingleses e chineses surge tão naturalizada que não precisa desse reforço descritivo.

É, portanto, do alto da experiência de nove anos nas Índias Ocidentais, onde presenciou o final da escravidão em colônias britânicas, e de cinco anos na China num momento crucial de imposição da política britânica que Forbes foi realocado em 1847, já como comandante do navio Bonneta, para o Esquadrão Africano, para patrulhar a costa da África Ocidental bloqueando o tráfico atlântico de escravos.

Interessante notar que, ao longo de sua carreira na marinha britânica, Forbes presenciou eventos importantes para a definição da relação inglesa com as regiões da América, África e extremo Oriente. Foi para as Índias Ocidentais exatamente no ano do decreto que abolia a escravidão nas colônias inglesas e para a China justamente no período final da Guerra do Ópio e da assinatura do tratado de Nanquim, em 1842, além de ter presenciado, na costa ocidental Africana, o período do final do tráfico atlântico de escravos. ${ }^{17} \mathrm{Em}$ resumo, pode-se caracterizar a posição oficial do governo inglês no que diz respeito às

\footnotetext{
${ }^{16}$ FORBES, F.E. Five Years in China... p. 3. Grifos meus.

${ }^{17} \mathrm{O}$ final do tráfico pode ser considerado um processo relativamente longo. Entretanto, Forbes estava na costa africana quando de um acontecimento chave, qual seja, a retirada do Brasil deste comércio, em 1850 .
} 
relações com as regiões acima mencionadas em meados do século XIX como uma defesa intransigente do livre comércio por oposição à ampliação de territórios coloniais e das antigas práticas monopolistas associadas a eles. 0 parlamento inglês na década de 1850, por exemplo, foi dominado pelos chamados radical free traders, defensores dessa linha de atuação. ${ }^{18}$

Esse liberalismo inglês, entretanto, não significava uma atuação pacífica, como o episódio da Guerra do Ópio já pode demonstrar. Lord Palmerston, por exemplo, ministro das relações exteriores no período de Forbes na África e um dos políticos mais importantes da primeira metade do século XIX na Inglaterra, era conhecido por ser adepto da "política do barco de guerra". ${ }^{19}$ As décadas de 1840 e 1850 são recheadas de exemplos da agressividade britânica ao redor do mundo, além da própria Guerra do Ópio. Essas atitudes não eram diferentes na costa africana, vide a postura do Esquadrão Africano, ao forçar tratados com estados da costa ocidental da África sob a mira dos canhões de seus navios ao menos desde a década de $1830 .{ }^{20}$ Também são exemplos dessa postura na África Ocidental o bombardeio da cidade de Lagos e a substituição do regente local em 1851, além do bloqueio ao comércio da costa ocidental durante meses na virada das décadas de $1840 / 1850 .^{21}$

É justamente da primeira experiência africana do autor, durante sua atuação no Esquadrão Africano, que vem o próximo texto a ser analisado aqui. Trata-se de um pequeno relato com cerca de 130 páginas, basicamente descrevendo a viagem de Forbes ao seu posto, a situação do comércio de escravos e a forma de atuação do Esquadrão Africano com algumas capturas de navios escravistas. Contrariamente ao que se podia esperar, entretanto, não se trata de um elogio à atuação dessa divisão da marinha britânica. Ao invés disso, o que surge ao longo do livro é uma crítica relativamente dura ao próprio esquadrão, do qual comandava um dos navios na divisão norte (no litoral compreendido então entre Serra Leoa e Libéria).

De fato, logo no prefácio, o autor apresenta claramente suas opiniões sobre os resultados da atuação do esquadrão africano. Começando com uma avaliação dos riscos dos comerciantes de escravos, Forbes sugere que,

o comércio escravo é altamente especulativo. Os grandes lucros resultantes deste comércio são dificilmente concebíveis e, dado o grande número de navios preparados para tal empreendimento, são quase certos. A lucratividade resultante é

\footnotetext{
${ }^{18}$ Ver CURTIN, Philip. The image of Africa, British Ideas and Action, 1780 1850. London: MacMillan \&Co., 1965.

${ }^{19}$ Ver HARGREAVES, John D. Prelude to the Partition of West Africa. London: Macmillan, 1966, p. 37. Palmerston foi duas vezes ministro das relações exteriores (Foreing Office Secretary), entre 1830-1841; 1846-1851; e também Primeiro Mministro entre 1855-1858 e 1859-1865, entre outros cargos ocupados no período.

${ }^{20}$ DIKE, K. Onwuka. Trade and politics in the Niger Delta 1830-1885, Oxford, Clarendon Press, 1956. Em especial o capítulo 4, para uma análise desta forma de atuação no Delta do rio Niger.

${ }^{21}$ Ver, por exemplo, SMITH, R. The Lagos consulate1851-1861: An Outline. The Journal of African History, vol. 15, n 3 (1974), p. 393-416.
} 
muito bem calculada pelo mercador; e apesar de ser uma loteria para as pessoas embarcadas, ele está suficientemente seguro. Ele prepara quatro navios e espera perder três; se ele perder apenas dois, considera-se sortudo. As capturas têm, assim, poucas consequências para o mercador de escravos, e certamente têm pouca utilidade no que diz respeito à supressão ou extinção do comércio. ${ }^{22}$

A grande lucratividade derivaria, segundo o autor, do pequeno valor do escravo na costa da África em contraposição ao seu alto preço nas Américas. Dessa forma conclui que "enquanto houver demanda, haverá escravistas". Até aqui, o argumento parece apenas reconhecer a incapacidade do Esquadrão de acabar com esse comércio. Não se tratava, afinal, de grande novidade, já que a Inglaterra patrulhava a costa africana há pelo menos 25 anos, e não conseguira ainda seu objetivo, a despeito dos vários tratados já existentes com Estados europeus e africanos tornando a venda de escravos ilegal.

Também não é grande surpresa a sugestão de política proposta pelo autor para a relação com a África Ocidental na forma de "um sistema de comércio útil e barato sob superintendência governamental, auxiliado por uma redução de preços inicialmente, mas sem a oferta de presentes. " ${ }^{23}$ Tal proposta teria a vantagem de 'educar' os africanos, "naturalmente indolentes", oferecendo grandes vantagens comerciais em troca de produtos africanos tais como azeite de dendê e marfim, por exemplo. ${ }^{24}$ Essa política demoraria para resultar em lucros para a Inglaterra, pois os africanos não se fariam "industriosos" de um dia para o outro. Mas, segundo Forbes, o exemplo de Serra Leoa mostra que teria resultado se a política fosse seguida com constância.

Entretanto, o que surpreende realmente é a sequência do argumento do autor. Uma vez que tal mudança, ou seja, a transformação dos africanos de "indolentes" em "industriosos" ainda demoraria um "longo tempo" para acontecer, a solução seria incentivar a "emigração" enquanto isso não ocorresse. E, mais ainda:

permitindo que o tráfico escravo ainda continue por alguns anos, não é de se supor que se venda mais do que 60 mil anualmente, fora os emigrantes. Os horrores da viagem transatlântica seriam, de qualquer forma, muito diminuídos pela retirada do bloqueio, não haveria o medo da captura, e assim os mercadores garantiriam que todos os navios fossem apropriados, e consequentemente seriam capazes de oferecer

\footnotetext{
${ }^{22}$ FORBES, F. E. Six Months' Service... p. v e vi da Introdução. Grifos meus.

${ }^{23}$ FORBES, F. E. Six Months' Service... p. vii.

${ }^{24}$ Embora não seja exatamente uma surpresa, lê-se aqui uma crítica quase direta à forma usual dos tratados anti-tráfico realizados entre a Inglaterra e os Estados africanos. Eles estavam justamente assentados na lógica de oferecer como recompensa pelo final do tráfico uma espécie de presente: um rendimento fixo durante um número limitado de anos para os governantes africanos com intuito de amenizar a diminuição de renda do Estado devido ao fim da lucrativa atividade do comércio escravo.
} 
mais liberalmente os espaços e a comida para os escravos embarcados. ${ }^{25}$

Dessa forma, o autor esboça um projeto de atuação para a Inglaterra na introdução de seu livro através do desenvolvimento do comércio visando a transformação do caráter geral do africano, mas sem a obrigatória supressão imediata do próprio tráfico escravo. Na verdade, segundo o autor, a atuação do "esquadrão africano" apenas pioraria a situação do africano que seria exportado de qualquer forma, como se pode notar na citação acima.

Como legitimação de seu argumento, Forbes apresenta a situação de Serra Leoa. No capítulo sobre a colônia inglesa, são recorrentes as imagens positivas: "cenas prazerosas", com vilas "bem construídas em locais pitorescos" nas quais "tudo tem a aparência de felicidade e conforto". ${ }^{26}$ Além disso, conclui o capítulo com a seguinte passagem:

foi objeto deste capítulo mostrar Serra Leoa, em sua relação com o comércio escravo; não deve ser considerado, assim, uma descrição da colônia nem devem as maneiras dos africanos liberados serem olhadas como particularmente descritivos de suas várias nações, mas talvez do que eles poderiam ser se tivessem as mesmas oportunidades abertas a eles, por meio do comércio justo e honesto. Como prova disto, diz-se que os Akoos ou Yarribas são a pior classe de idólatras, e certamente os maiores traficantes de escravos de toda a costa. Ainda assim, eles se saem melhor do que quaisquer outros. ${ }^{27}$

Assim, Forbes procurava demonstrar a funcionalidade da educação e do "comércio justo e honesto" mesmo sobre a pior "classe de idólatras" e ao mesmo tempo defender a ideia da presença da tutela britânica como forma de assegurar a consecução desses objetivos. Ressalte-se, entretanto, que essa presença deveria ser apenas no gerenciamento das atividades coloniais, garantindo a liberdade de comércio. Já o bloqueio ao tráfico escravo, como se viu, não aparecia sob as mesmas luzes para o autor.

De fato, ao longo do texto, Forbes procura mostrar que tal atividade apenas piora as condições dos africanos que seriam exportados como escravos de qualquer jeito. Nem mesmo as mais violentas ações poriam fim a esse comércio, enquanto houvesse demanda:

...queime todas as fábricas; limpe toda a costa da África do tráfico escravo; torne-o pirataria; enforque o capitão, ou todos; e a menos que os governos do Brasil e Cuba entrem de corpo e alma no trabalho de suprimi-lo, tão logo o esquadrão seja

\footnotetext{
${ }^{25}$ FORBES, F.E. Six Months' Service... Introdução, p. Viii.

${ }^{26}$ FORBES, F.E. Six Months' Service... . p. 15.

${ }^{27}$ FORBES, F.E. Six Months' Service... . p. 27.
} 
diminuído, o comércio vai ser reaberto com horrores redobrados. ${ }^{28}$

Horrores esses que eram ampliados paradoxalmente pela própria presença do esquadrão em costas africanas, o que fazia com que as estratégias de embarque de escravos para as Américas fosse arriscada e aumentasse o sofrimento daqueles escravizados. De acordo com o autor, se o africano fosse embarcado próximo ao barracão de armazenamento seus sofrimentos seriam limitados ao tempo em que passava à espera do embarque, o que já não era pouco. As descrições dos barracões ressaltam as condições de insalubridade, alimentação insuficiente, maus tratos e mortes.

Mas, se o bloqueio funcionasse adequadamente, os africanos eram forçados a marchar milhas pela costa até um ponto adequado e livre para o embarque se isso fosse possível. Nesse caso, o sofrimento era ainda maior. Nas palavras do autor:

...a miséria sofrida pelo escravo durante este período só pode ser imaginada. Constantemente forçado a marchar distâncias de setenta a oitenta milhas, o aumento dos custos e frequentemente a ausência de provisões faz com que praticamente morram de fome; ou talvez que sejam mortos (como no caso de 2 mil deles em 1847) pela falta de provisões para mantê-los. ${ }^{29}$

Para resumir as opiniões de Forbes sobre o estado da situação e seus projetos, pode-se dizer que ele condenava o tráfico de escravos, mas também o funcionamento da repressão inglesa, que só tornava piores os sofrimentos dos africanos. O livre comércio e a cristianização como forma de educação da população seriam os remédios de longo prazo cujo funcionamento era demonstrado pela situação da colônia de Serra Leoa, e, a curto prazo, a surpreendente afirmação de que o tráfico deveria ser permitido para diminuir os horrores sofridos pelos escravizados na costa.

Trata-se de uma opinião pouco ortodoxa, em especial nas críticas ao esquadrão e na ideia de liberalização do comércio escravo. Mas essas opiniões não durariam muito tempo. Em seu relato sobre as viagens para o Daomé, logo no início do livro, Forbes muda de perspectiva de maneira radical. Dessa forma, informa qual seu objetivo ao escrever o livro:

...ilustrar as temíveis caçadas de escravos e suas destruições, aniquilações e extermínios consequentes do comércio escravo; e mostrar de forma proeminente ao público britânico o serviço sagrado que eles estão prestando aos seus irmãos humanos, ao encorajar esforços crescentes para estancar estes terríveis horrores. $^{30}$

\footnotetext{
${ }^{28}$ FORBES, F.E. Six Months' Service... .p. 97.

${ }^{29}$ FORBES, F.E. Six Months' Service... . p. 84

${ }^{30}$ FORBES, F.E. Dahomey and the Dahomans... p. iv do prefácio.
} 
A retórica do prefácio continua intensa, procurando talvez despertar as emoções do leitor e ao mesmo tempo afirmar a experiência adquirida pelo autor não apenas na África, mas em todos os espaços da "escravidão". Assim, ele já havia presenciado nas costas africanas o tráfico escravo "em seu estágio sistemático e avançado", e os horrores dali oriundos; também já visitara os barracões e vira homens tão extenuados que não conseguiam "suportar o próprio peso"; estivera também a bordo de um navio escravista, e vira as "doenças surgindo em razão do excesso de pessoas para pouca comida e água ", finalmente, também já presenciara o trabalho escravo nas Américas, e sabia que o senhor calculava com razão que valia mais a pena exaurir e matar o escravo de tanto trabalhar para depois adquirir outro, do que "postergar sua miserável existência."

Mas o que seriam essas cenas trágicas - pergunta o autor - frente àquelas que introduzem o escravo na escravidão?
Um país vivendo em paz com todos em sua volta, e buscando o comércio com a intenção de enriquecer é subitamente cercado por rudes bandidos; e como muda a cena! Os velhos que seriam rejeitados no mercado são sacrificados; toda a nação é transportada, exterminada, seu nome deixado para ser esquecido... ${ }^{31}$

A raiz de todos esses males era o próprio tráfico escravo. E a situação permaneceria enquanto tal atividade continuasse. Qual seria a solução? Ora, surpreendentemente para aqueles que conhecem seu relato sobre o bloqueio, escrito cerca de um ano antes, a resposta aponta exatamente para o Esquadrão Africano! Segundo ele, fatos e não opiniões devem ser usados para comprovar o argumento: 11 navios escravistas haviam sido capturados na divisão norte (entre a Libéria e Serra Leoa) no ano de 1848 e, com isso, naquele momento, o tráfico acabara completamente. ${ }^{32}$

Uma mudança tão radical de atitude e perspectiva carece de uma explicação! O próprio Forbes reconhece isso e sugere que o erro de julgamento cometido era explicável. Ele não culpava aqueles que acreditavam que o "esquadrão ampliava os horrores", mas sugeria que tal equívoco derivava do desconhecimento da "origem dos males" relatados, ou seja, as capturas de escravos, e continuava informando que "se o esquadrão for retirado, as caçadas de escravos e os extermínios aumentariam ". 33

Entretanto, a despeito da imagem construída sobre as caçadas de escravos com as cenas trágicas dos velhos sendo mortos e de 'nações' que desapareciam do mapa após os ataques, parece bastante claro que Forbes não presenciou nenhuma atividade tal como a referida. De fato, o autor não passou

\footnotetext{
${ }^{31}$ FORBES, F.E. Dahomey and the Dahomans... p. v.

32 Diógenes teria mais chance de encontrar um homem bom do que um cruzador britânico de encontrar um navio escravista. FORBES, F.E. Dahomey and the Dahomans... p. vii.

${ }^{33}$ FORBES, F.E. Dahomey and the Dahomans... p.viii.
} 
nem mesmo perto de regiões devastadas após as batalhas para captura de escravos. ${ }^{34}$ Assim, seria preciso mostrar a violência e a 'barbárie' em outros lugares e, aparentemente, o Daomé apresentava-se como o espaço ideal para isso.

Nesse sentido, é significativa a afirmação de Forbes ao chegar em Aladá, a cerca de quarenta quilômetros de Uidá. Segundo ele, naquele momento sentiu que havia "entrado no reino do Daomé". E a razão pela qual sentiu isso foi porque vislumbrou uma caveira humana sobre o muro do palácio e, no pátio interior, três corpos ainda em estado de putrefação, fixados em árvores. ${ }^{35}$ Frente aos vestígios de sacrifícios humanos, o autor finalmente havia entrado no bárbaro reino africano.

Note-se, como outro exemplo da narrativa, a seguinte passagem, quando Forbes encaminhava-se para assistir mais uma parte das cerimônias dos costumes anuais daomeanos:

Quando chegamos à quadra do palácio, ao pé da ladeira que levava à casa de debates, em cada lado havia três cabeças humanas recentemente decapitadas, o sangue ainda escorrendo; ao pé do portão de entrada havia uma piscina de sangue dos seis sacrifícios humanos, sobre a qual tivemos que pular. ${ }^{36}$

Nessa citação, a descrição é reforçada pelas passagens que sugerem a presença impositiva dos horrores dos sacrifícios. O autor não os presenciara, mas eram tão recentes que era possível ver ainda o "sangue escorrendo". Como se não bastasse, formara-se ali uma "piscina de sangue". Essa é uma passagem significativa; na mesma página, lê-se duas vezes a palavra sangue, três vezes caveira, e outras três Cabeças humanas. Sem dúvida, Forbes estava estabelecendo a imagem de um espaço e de seus emblemas "bárbaros e nojentos". 37

Desse momento em diante, trechos como o mencionado acima tornamse relativamente frequentes no relato. Tome-se mais um exemplo desse tipo de retórica:

...tais tambores são ornamentados com uma ou duas dúzias de caveiras, interlaçadas com mandíbulas. Um guarda-sol, que fazia sombra à uma princesa negra, estava decorado com 148 mandíbulas humanas, e cada uma destas moças - além de serem atendidas por escravos que carregavam espadas e

\footnotetext{
${ }^{34}$ Obviamente não se trata em nenhum momento de ignorar a reconhecida violência das batalhas para captura de escravos na África Ocidental e suas consequências realmente trágicas para as sociedades atacadas, e sim de notar que o viajante não foi testemunha de nenhuma delas.

${ }^{35}$ FORBES, F.E. Dahomey and the Dahomans... p. 56, vol. 1.

36 FORBES,F.E. Dahomey and the Dahomans... p. 33-34, vol. 2. Grifos meus.

${ }^{37}$ FORBES, F.E. Dahomey and the Dahomans... p. 34. A frase do autor é "...ornamented with emblems of human and bullock's heads, skulls, and other devices equally barbarous and disgusting".
} 
escudos além daqueles ornamentos repelentes - portavam em seu cinto um copo feito de caveira humana polida. ${ }^{38}$

Para o autor, não se trata de apenas ressaltar a existência de sacrifícios humanos, o que seria por si só bastante repulsivo para o público inglês, leitor alvo de seu texto. Mas de multiplicar e pormenorizar os exemplos. O guarda-sol era enfeitado com "148 mandíbulas humanas". Faz pensar no trabalho que deve ter lhe dado contar tais ornamentos. Além disso, dos escravos às princesas, todos usavam como penduricalhos caveiras e mandíbulas.

Uma última passagem que merece menção aqui diz respeito novamente à cerimônia de sacrifícios humanos. No despacho do Comodoro Arthur Fanshawe para Forbes, de setembro de 1849, sobre seus procedimentos para a visita ao Rei Gezo, não consta nenhuma orientação para evitar a presença inglesa nos rituais de sacrifícios humanos. ${ }^{39}$ Tais orientações, entretanto, já estariam presentes cerca de uma década depois, nas instruções para Richard Burton em sua missão no Daomé, em 1863. ${ }^{40}$ No caso de Forbes, o seu testemunho dos sacrifícios humanos gera alguma dúvida no leitor, visto que por encontrar-se "enojado além da possibilidade de descrição", retira-se para seu assento, acompanhado do então Chachá Inácio (filho de Francisco Félix de Souza, recentemente falecido), e lamenta informar que os irmãos do Chachá "permaneceram como espectadores deliciados das agonias da morte destas vítimas inocentes". 41

Entretanto, logo após, descreve a cerimônia como se presenciasse tudo, como se percebe na seguinte citação:

...tendo a vítima sido jogada de cerca de 3,5 metros de altura, no pátio abaixo [...] a queda deve tê-lo atordoado, e antes que os seus sentidos pudessem retornar, a cabeça foi cortada, e o corpo lançado à multidão, que, agora armada com bastões e galhos, mutilaram brutalmente e arrastaram o corpo para um buraco distante, onde foi deixado como presa para as bestas e os pássaros [...] espera-se que uma nação que pratica tais atos imbecis seja logo forçada a consertar suas maneiras e mudar seus costumes. ${ }^{42}$

Pode-se ver, portanto, que a descrição do Daomé oferecida por Forbes apresenta características que não são muito diferentes de seus contemporâneos, e mesmo de seus colegas de missão. John Duncan também representa o Daomé carregando nas tintas vermelhas, por assim dizer. Em seu relato não faltam referências ao sangue ainda quente jorrando de pescoços sem

\footnotetext{
${ }^{38}$ FORBES, F.E. Dahomey and the Dahomans... p. 38, vol. 2.

${ }^{39}$ King Gezo of Dahomey 1850-52. London: the Stationery Office, 2001. p. 15.

${ }^{40}$ Public Record Office, Documentos do Foreign Office, Série 84/ 1203 de 20/08/1863.

${ }^{41}$ FORBES, F.E. Dahomey and the Dahomans... p.51, vol. 2.

${ }^{42}$ FORBES, F.E. Dahomey and the Dahomans... p. 52-53, vol. 2.
} 
cabeça. ${ }^{43} \mathrm{O}$ Daomé era então tratado na Inglaterra, entre os círculos humanitários e filantropos, como o grande inimigo do avanço da civilização no interior da África Ocidental, cujo representante maior era Serra Leoa, seguido de perto por Abeokuta, the Sunshine within the Tropics. ${ }^{44}$

É momento, portanto de tentar compreender a mudança de ideia de Forbes com relação à atuação do Esquadrão Africano em tão pouco tempo.

\section{Considerações finais}

Não resta dúvida de que Forbes pode ser classificado como um defensor dos ideais humanitários que se constituíam em importante força política no parlamento inglês até, ao menos, o início da década de $1850 .{ }^{45}$ Obviamente isso não significava nenhuma ideia de igualdade entre todos os povos da terra, mas sim a necessidade e o dever da Inglaterra de tutelar os 'povos inferiores' em direção ao desenvolvimento da civilização, o que queria dizer basicamente: cristianismo, trabalho e comércio livres. ${ }^{46}$

Assim, na descrição da população chinesa, pode-se notar certa condescendência de Forbes, e mesmo uma relativização mostrando que os chineses, apesar de tudo, podiam estar à frente dos ingleses em algumas coisas. A situação na China, afinal, estava exatamente de acordo com a vontade Inglesa, em especial depois de 1842 . Isso a despeito do fato do uso da força para impor as dinâmicas comerciais inglesas, significativamente silenciadas pelo autor ao longo de seu relato.

A crítica veemente do autor contra o tráfico de escravos em praticamente todos os seus textos também aponta para a concordância de Forbes com esses ideais filantrópicos e humanitários. De fato, o autor tornarse-ia um pequeno ícone dessa perspectiva em razão de um acontecimento derivado de sua viagem ao Daomé e mencionado, apenas de relance, nas páginas finais de seu texto. Trata-se do resgate de uma criança africana que estava prestes a ser sacrificada. Essa jovem foi batizada como Sarah Forbes Bonneta, ou seja, o prenome seguido do sobrenome de Forbes e do nome do

\footnotetext{
${ }^{43}$ Ver para apenas uma das passagens com esta conotação no relato de Duncan sobre viagem ao Daomé escrito alguns anos antes. DUNCAN, John. Travels in West Africa in 1845-1846, comprising a journey from whydah to the kingdom of Dahomey, to Adofoodia. London: Richard Bentley, 1847, pp. 252-253. Neste trecho, Duncan refere-se ao sangue jorrando, e a velhos correndo para bebe-lo enquanto ainda escorria do pescoço decapitado.

${ }^{44}$ TUCKER, Sarah. The Sunrise Within the Tropics, na outline of the origin and progress of the missions in Yoruba. London: James Nisbet and Co., 1853. Em certo momento, a autora cita Samuel Crowther, o primeiro bispo anglicano negro, falando de Abeokuta e sua relação com o Rei Gezo: 'Este', disse o Mr. Crowther, 'é o único lugar onde a luz do evangelho brilha. Com certeza, Deus não o deixará ser esmagado, nem permitirá ele que os trabalhos da Inglaterra para a destruição do tráfico escravo e conversão da África seja frustrado por um tirano sedento de sangue"'p. 208.

${ }^{45}$ Para uma avaliação das concepções políticas desta parcela do parlamento com relação à África no período ver: CURTIN, P. The Image of Africa, British ideas and action, 17801850. London, MacMillan \&co.,1965.

${ }^{46} \mathrm{Com}$ a ressalva de que se entende por 'comércio livre' aquele que satisfazia os desejos e necessidades inglesas, como a Guerra do Ópio pode claramente mostrar.
} 
bergantim que ele capitaneava no Esquadrão Africano. Sarah tornar-se-ia, quando na Inglaterra, afilhada da própria rainha Vitória. Forbes esperava que ela, "um perfeito exemplar frenológico", pudesse demonstrar que o intelecto da 'raça negra' podia se desenvolver tanto quanto o dos europeus. ${ }^{47}$

Portanto, não há grande segredo no posicionamento de Forbes sobre a política para com a África. Por um lado, defendia a condição de civilização dos nativos africanos, mas, por outro, advogava a intervenção e o uso da força, se necessário, para levar tal objetivo à sua consecução. $O$ problema seria apenas conciliar, de um lado, uma população capaz de civilizar e, de outro, seus costumes bárbaros. O próprio autor considera estranha essa mistura.

Num país bárbaro como o Daomé, é curioso descobrir que a dinastia já durou dois séculos. Muitos de seus costumes estão estranhamente em divergência com os horrores de outros. As formas e cerimônias da sociedade polida contrastam curiosamente com os sacrifícios de seus prisioneiros de guerra. $^{48}$

Entretanto, uma vez constatada essa 'estranha divergência', alguma atitude precisaria ser tomada. E ela parecia passar pelo uso da força, como sutilmente sugerido na citação sobre os sacrifícios humanos. Realmente, o autor também defende o uso da força em outro momento do relato, quando sugere que seriam necessárias duas "conquistas", uma social e moral e outra coercitiva. Mesmo que "os amantes da paz" pudessem não gostar do termo coerção, era apenas através da imposição de tratados forçados, associada à educação religiosa, que seria possível fazer no Daomé o que Forbes supunha já ter sido feito em outros lugares da costa da África Ocidental. ${ }^{49}$

O cuidado com as palavras quando recomendava a coerção frente ao Daomé ressoa aos debates em Exeter Hall na Inglaterra. Uma década antes, em 1840, os delegados da convenção internacional da Anti Slavery Society haviam votado em massa contra a ideia do uso da força como solução para combater o tráfico escravo, permanecendo fiéis aos "princípios morais, religiosos e pacíficos" da associação. ${ }^{50}$

\footnotetext{
${ }^{47}$ FORBES, F.E. Dahomey and the Dahomans... p. 208, vol. 2.

${ }^{48}$ FORBES, F.E. Dahomey and the Dahomans... p. X, vol. 1. A própria caracterização do Rei Gezo aponta também para este contraste entre costumes bárbaros por um lado e polidos por outro. Segundo Forbes "nenhum rei poderia mostrar mais civilidade e ser mais condescendente" idem, p. 80, vol. 1.

${ }^{49}$ Como exemplo, ele cita entre outros o Delta do Niger. Segundo o autor, ali os habitantes tremiam de desgosto frente à ideia de vender seus homens, e as superstições pagãs estão retrocedendo frente aos passos da cristandade. FORBES, Dahomey and the Dahomans... p. 142 , vol. 1. Não deixa de ser irônico que Bonny, no Delta do Niger seja descrito mais de uma década depois como adornada com caveiras humanas, de forma bastante parecida com a qual Forbes descrevia o Daomé. Ver BURTON, Richard. Wanderings in West Africa. London: Bentley, 1863.

${ }^{50}$ GREEN, William. The West Indies and British West African policy in the Nineteenth Century A corrective Comment. The Journal of African History, vol 15, n 2, 1974, pp 247-259. p 254.
} 
Dessa forma, parece que Forbes estava, até o momento da sua viagem para o Daomé, imbuído da ideia de que o uso da força não deveria ser incentivado, especificamente com relação à África. Ressalte-se aqui, para reforçar o argumento, o silêncio constrangido do autor sobre os embates que havia presenciado alguns anos antes no extremo oriente e também a própria sugestão da inutilidade do Esquadrão Africano no combate ao tráfico, sob o argumento de que aumentaria o sofrimento dos africanos escravizados.

A mudança de opinião então precisava ser legitimada, e encontrou sua legitimação na caracterização do Daomé como extremamente bárbaro. Assim, a ênfase nas descrições dos horrores presenciados na África Ocidental parece ganhar um sentido mais amplo no contexto dos escritos de Forbes ao longo do tempo.

Resta ainda também um último argumento, qual seja, a relação, ainda que indireta, entre o Esquadrão Africano e as Índias Ocidentais inglesas. Segundo William Green, a presença dos navios ingleses no combate ao tráfico escravo na costa africana derivava mais da pressão dos fazendeiros nas colônias que, desde 1833, não podiam mais utilizar trabalho escravo e encontravam-se sem condições de concorrer internacionalmente no mercado produtor de açúcar, do que propriamente dos escrúpulos humanitários de Exeter Hall. Esses últimos, porém, haviam sido extremamente importantes justamente na pressão para o final da escravidão. ${ }^{51}$

Por outro lado, mesmo após 1833, as Índias Ocidentais continuaram recebendo trabalhadores africanos vindos dos programas de 'emigração voluntária' propostos pela Inglaterra para os escravos capturados justamente pelo Esquadrão Africano. Entre 1841 e 1867, cerca de 36 mil africanos foram transportados de Serra Leoa e Santa Helena para as colônias americanas. ${ }^{52}$ É possível assim perceber que uma grande parte dos africanos capturados pelo Esquadrão continuava encontrando seu caminho até as estruturas produtivas da América.

Frente a essas considerações, pode-se talvez adicionar mais um elemento à explicação para a mudança de opinião de Forbes sobre a validade do uso da força e, portanto, do trabalho do Esquadrão Africano, quando de sua visita ao Daomé. Dessa forma, é possível perceber que uma série de elementos interagem na mudança da perspectiva do autor sobre a atuação inglesa na costa africana em seu período como comandante do navio Bonneta.

Em primeiro lugar, não se deve desconsiderar a impressão que a visita ao Daomé tenha causado no autor. A visão dos sacrifícios humanos, e de seus vestígios, certamente deve ter tido um grande impacto na perspectiva do autor. Aparentemente foi a primeira vez que Forbes entrou em contato com regiões no interior da África, e o enorme estranhamento pode sem dúvida ter afetado sua imagem do continente.

${ }^{51}$ GREEN, William, The West Indies and British West African policy ... Apesar disto, ainda segundo Green, a importância do lobby dos fazendeiros no parlamento inglês pode ser demonstrado pelo tamanho da indenização recebida por eles quando da proclamação do final da escravidão: 20 milhões de libras.

${ }^{52}$ GREEN, William, The West Indies and British West African policy...p. 257. 
Mas também não se pode desprezar a possibilidade de que esse tempo no litoral e no interior da África Ocidental tenha Ihe chamado a atenção para a importância do Esquadrão Africano para a imposição de um funcionamento mais amplo da política inglesa para toda a bacia do Atlântico. Muito além do combate ao tráfico, a presença da marinha britânica na costa africana passava cada vez mais a exercer outras funções tais como o fornecimento indireto de trabalhadores livres para as Índias Ocidentais, a proteção das iniciativas comerciais de grandes firmas inglesas que investiam no comércio de óleo de palma, bem como a garantia da imposição das dinâmicas comerciais pretendidas pela Inglaterra sobre as duas costas do Atlântico.

É, portanto, preciso ler o relato de Forbes dentro dessa perspectiva mais complexa, na qual a sua retórica, suas ênfases, temas e silêncios adquirem sentido não apenas dentro do arcabouço humanitário e filantrópico do autor, mas também frente à dinâmica imperial inglesa na metade do século XIX.

Enfim, para um autor comprometido com os ideais de Exeter Hall, o uso da força só podia se legitimar através de uma representação da barbárie exacerbada de uma região africana. Barbárie essa que não derivaria diretamente de quaisquer características intrínsecas da 'raça' negra, mas sim de uma conjuntura histórica que estava profundamente conectada com 0 desenvolvimento do tráfico atlântico de escravos.

Significativamente - e embora esta interpretação não apareça diretamente nos textos do autor - esse mesmo uso da força ou coerção serviria para garantir, ao menos em parte, o funcionamento dos dois grandes "experimentos filantrópicos" organizados pela Inglaterra no período, ou seja, uma região colonial produtora de açúcar com trabalho livre (as Índias Ocidentais) e outra supostamente autogerenciada na costa africana (Serra Leoa). 